\title{
Obesity, Complexity, and the Role of the Health System
}

\author{
Sarah Frood • Lee M. Johnston • Carrie L. Matteson • \\ Diane T. Finegood \\ Published online: 30 August 2013 \\ (C) The Author(s) 2013. This article is published with open access at Springerlink.com
}

\begin{abstract}
As obesity continues to increase throughout the world, there is still no well-defined solution to the issue. Reducing obesity poses a significant challenge for the health care system because it is a complex problem with numerous interconnections and elements. The complexity of obesity challenges traditional primary care practices that have been structured to address simple or less complicated conditions. Systems thinking provides a way forward for clinicians that are discouraged or overwhelmed by the complexity of obesity. At any given level, individuals matter and system functioning is optimized when our capacity is well matched to the complexity of our tasks. Shifting paradigms around the causes of obesity is essential for creating a health care system that promotes innovative and collaborative practice for healthcare practitioners and individuals dealing with obesity.
\end{abstract}

Keywords Obesity · Complexity · Systems thinking · Paradigms $\cdot$ Capacity $\cdot$ Feedback $\cdot$ Primary care .

Health system

\section{Introduction}

Obesity rates are increasing worldwide and although it is recognized by the World Health Organization as one of the 'greatest public health challenges of the twenty first century',

S. Frood $\cdot$ C. L. Matteson $\cdot$ D. T. Finegood $(\bowtie)$

Chronic Disease Systems Modelling Lab, Department of Biomedical

Physiology and Kinesiology, Simon Fraser University,

8888 University Drive, WMC 2805, Burnaby BC V5A 1S6, Canada

e-mail: dfinegood@msfhr.org

S. Frood

e-mail: sfrood@sfu.ca

C. L. Matteson

e-mail: carrie_matteson@sfu.ca

\section{M. Johnston}

Faculty of Health Sciences, Simon Fraser University, 8888 University Drive, Burnaby BC V5A 1S6, Canada

e-mail:1mjohnst@sfu.ca there is still no clear, well-defined solution [1]. Reducing obesity poses a significant challenge because it is a complex problem with numerous interconnected variables. Experts suggest that influencing this complex web of interdependent parts will require a holistic, integrated response from various sectors $[2,3]$. The healthcare sector has the potential to play an important role in this approach. Unfortunately, current practices in health care do not usually treat obesity as a complex problem and practitioners are left with minimal resources to address an overwhelming issue [4]. In this review we consider the challenges that the complexity of obesity presents to the healthcare sector, and the ways in which the field is evolving in response. Using examples of how complexity and systems thinking can shift health care practices in addressing obesity, we demonstrate that accepting this complexity can help health care move past common responses to complex problems and work toward more effective solutions.

\section{Obesity as a Complex Problem}

There are several models of obesity's causality and they range in their depiction of complexity. Obesity research predominantly focuses on biomedical models in an attempt to isolate specific physiological causal mechanisms at the level of the individual $[4,5 \cdot, 6]$. According to the biomedical perspective, obesity is essentially the result of an energy imbalance driven by individual behavior wherein energy intake exceeds energy expenditure over time [5•]. This approach has had significant implications for obesity treatment and prevention, influencing clinical practice and government policy in spite of the evidence against its effectiveness at the population level [5•]. The past few decades have seen a shift toward a socio-ecological view of obesity, in which individual behavior is situated within a broader social context. The socio-ecological model takes economic, cultural, and political determinants into consideration and presents individual obesity as at least partially influenced by forces external to the individual [7, 8]. It presents obesity as being complicated, but falls short of accounting for the characteristics of complexity embodied by obesity $[7,9,10]$. 
Understanding obesity as a consequence of complex interactions between many variables has been an important milestone for obesity research. Hamid [11] suggests that system complexity is driven by the number of elements and the degree and nature of the interactions between them. The Foresight group has developed a model that effectively displays these and other characteristics of complexity, framing obesity as a property emerging from over 100 variables and 300 interconnections [12]. The diversity within the multiple elements, which can range from variability in an individual's genetic makeup, to the quality of food formulation to individual psychology, reflects the heterogeneity characteristic of complex systems. The model also depicts numerous feedback loops, the presence of which demonstrates interdependence and nonlinear relationships between system components [13].

Like socio-ecological models, the Foresight map illustrates the diversity and broad range of influences on individual behavior. For example, an individual's' food choices can be influenced by the price of food, the availability of food, the biological responses to the reward value of food and the cultural meaning of food [14]. Furthermore, systems typically have "fuzzy" boundaries, such that pushing on one part of the system can have unintended consequences in other areas or systems [15]. The Foresight map successfully communicates these interdependencies and the real difficulty of dealing with complex social problems. Relationships are furthermore difficult to predict in complex systems due to time delays between actions and results [11]. This is true regarding individual weight gain as well as population level weight loss. The length of time required to see significant results therefore complicates prevention efforts [11]. Biomedical, socio-ecological and complex models all contribute to our understanding of obesity and are needed to inform our efforts to intervene. The variations between them, however, highlight the need for different approaches to problems based in part on their complexity.

\section{Current Practices in Obesity Prevention and Treatment}

Despite the evolution in our understanding of obesity as a complex problem, the most common approach to obesity treatment is to view it as a simple problem and attempt to change individual behavior by changing energy balance, primarily through health education $[2,6,11]$. Clinical treatment options include behavioral, cognitive, surgical and pharmaceutical therapies. Bariatric surgery has shown significant success in treating obesity however access to patients is limited for a variety of reasons, including long wait lists and the invasive nature of surgery [16]. Pharmacotherapy has been associated with modest weight loss yet requires more research regarding long-term health benefits and safety [17]. Lifestyle interventions remain the foundation of obesity treatment as they are the least invasive option. However, adherence to programs is poor and patients experience a lack of long-term success [18].

Although lifestyle intervention is a cornerstone of clinical treatments for obesity, there are many barriers to its widespread application. Physicians may be poorly equipped in that they lack training in weight loss strategies and obesity management, and do not have the appropriate strategies to support recommendations to eat less and move more [19]. Research has also suggested that the stigma associated with obesity complicates health care interactions, impacting patient experiences and the quality of care received [20]. Structural barriers to effective care include a lack of appropriately sized equipment, insurance schemes that do not cover obesity and lack of access to interdisciplinary care teams whose multifaceted expertise matches the complexity of the problem [19]. The complexity of obesity challenges traditional primary care practices that have been structured to address typically acute and less complicated conditions. For practitioners, addressing obesity as a simple problem has produced discouraging results with clinicians often reporting obesity treatment as being "doomed to failure", frustrating and ineffective $[19,21-23]$.

\section{Applications of Systems Thinking}

In spite of the challenges posed by obesity, evidence suggests that primary care physicians have an important role to play in delivering preventive services, as their counseling can be effective when offered [24]. Unfortunately, physicians are often reluctant to advise their patients on weight loss [24]. Applying a complex systems lens to the prevention and treatment for obesity could prove to be a promising strategy for improving obesity treatment.

\section{Matching Capacity to Complexity}

Many of the systems-based strategies for addressing obesity relate to the core principle of capacity building. Health education strategies are rooted in the notion of building selfefficacy in order to promote behavior change, and evidence suggests that providing physicians with the right tools for the job can improve outcomes [25]. Increased knowledge of weight loss diets among health care professionals, for example, is associated with less dislike of discussing weight loss with patients, less frustration and less belief that treatment is ineffective [22]. For the most part, however, health education proves unsuccessful in creating long-term behavior change. This suggests that education may only increase capacity marginally, or that other factors may be too influential on behavior to make education an efficient target for creating change [26••]. Systems theorists note that when the capacity of an individual is mismatched with the complexity of the task at 
hand, the individual is more likely to fail [26••, 27]. For example, clinicians in a typically busy health care practice may avoid discussing obesity with patients if they feel constrained by the need to keep clinical visits short, a large patient load, minimal resources and a poor understanding of effective treatments. On the other hand, a clinician with a smaller patient load, with access to information regarding best practices and with a supportive collaborative healthcare team may be better prepared to address the complexity of an individual's obesity. A patient that is overwhelmed by the complexity of behavior change may be resistant to treatment or advice from a health practitioner if they feel judged or stigmatized in the clinical setting and this may impact their own capacity to deal with the issue. Complex systems research shows us that even in highly complex systems, individuals matter [27].

Ideally, other actions should be considered in tandem with health education that would address the relationship between individuals and their environment [28]. In practice, there are limits to the extent of intervention a physician can provide to a patient navigating the complexities of their own individual environment. One strategy for primary care would be to reduce the complexity of the task at hand by focusing on the process, as opposed to the desired outcome. This approach aligns with basic principles of behavior change efforts to break goals down into smaller, regularly achievable actions [29-31], rather than reaching for overwhelming changes [32]. A clinician could practice this by encouraging a patient to aim for a certain number of steps walked per day, as opposed to focusing solely on the desired amount of weight loss over a certain time frame.

Tools are currently being developed to engage patients with management of their 'system'. The 5As counselling framework is one such tool that has been proposed to help guide physicians through obesity counseling [33, 34]. Physicians are instructed to assess risk, current behavior, and readiness to change; advise change of specific behaviors; agree and collaboratively set goals; assist in addressing barriers and securing support; and arrange for follow-up [33, 34]. Another potential tool involves the use of patient-physician communication cards, which have been successfully employed in the treatment of diabetes [35] and are being tested for applicability to obesity in order to improve patient outcomes. In a recent pilot study, patients sorted cards based on summaries of the complex factors associated with obesity to highlight the determinants of obesity that were meaningful to them. The results found that prioritizing cards that were important to the individual had the potential to create a more efficient clinical visit by improving the conversation around obesity between patient and healthcare practitioners [36]. Moreover, the act of prioritizing values proved helpful in providing feedback to patients on their progress to date [36].

Many patients demonstrate insufficient knowledge of their medical conditions and uninformed patients are less likely to use preventive services [37, 38]. Addressing patient engagement and promoting shared decision-making in health care provides an example of using systems thinking to improve patient knowledge and ultimately improve their health outcomes. Koh et al. [39•] proposed a Health Literate Care model to address patient engagement by weaving health literacy strategies into the already existing and widely popular Care Model. Increasing patient engagement likewise increases the capacity of individuals dealing with their health conditions, while also benefitting health care organizations by improving health practitioner and patient communication. The model improves upon current primary care, where programs to support patients in these areas are not yet well developed or widely implemented [40].

The Health Literate Care Model demonstrates a holistic, systems-based approach by treating health literacy as an organizational value infused into all aspects of planning and operations, including self-management support [39•]. A health literacy team is assigned the tasks of championing strategies, identifying targets and monitoring results. Creating a health literacy team has the additional benefit of establishing a network of like-minded thinkers that have the potential to increase awareness among the rest of the organization. The model increases organizational capacity by addressing the complexity inherent to health care systems [15, 41, 42]. Improving collaboration among health practitioners and throughout system sectors has been identified as a means of improving the standard of care [43]; the model succeeds by facilitating collaboration. Finally, the model places an emphasis on feedback through patient surveys and constant assessment of methods [39•]. This study proposes a practical systems framework for improving patients' health literacy with the hope of improving the patient experience and ultimately improving health. By adopting a systems based approach, the study not only increases the capacity of individuals within the health care organization but also creates an environment that encourages communication, feedback and continuous assessment and improvement.

\section{Knowledge Exchange and Feedback}

The flow of information holds powerful influence over system functioning [44]. Opportunities to obtain feedback, initiate dialogue and leverage a diversity of perspectives has the potential to significantly change system behavior by improving information flows and shaping relationships between system members [42]. Leischow and Milstein [45] suggest that relationships are 'the heart of a systems orientation'; building on those relationships to increase collaboration among system members is essential and can be further improved with successful knowledge exchange. Health care organizations would be served by identifying influential leaders who value collaboration as they can have a key role in establishing effective 
networks [46], thereby enhancing knowledge exchange. Influential leaders should model the openness, risk taking and reflection necessary for learning, and communicate a compelling vision of the required organizational change, providing the support and personal advocacy needed to lead others toward it [47].

Connecting individual practitioners with like-minded thinkers and creating the conditions for new approaches and knowledge exchange can promote emergence [48]. Emergence is the system property wherein novel structures and patterns develop during the process of self-organization in complex systems [26••]. Wheatley and Frieze [48] suggest that emergence is a means of turning local changes into meaningful shifts for system-wide change. When local actions occur in isolation, their impact is limited to that area. Connecting local activities to one another has the power to form networks. Networks have fluid membership and can trigger 'communities of practice' where new knowledge and ideas are quickly shared with a wider audience. Eventually, 'communities of practice' can grow into a 'system of influence' where the novel and innovative ideas or efforts become the norm, are easily adopted by others, and spread throughout a system [48]. Complex health issues requiring multifactorial solutions can benefit from the establishment of new networks made up of diverse parties. Mascia et al. [49] found physicians more likely to collaborate with those that share similar traits. While this facilitated collaboration in decision making, creating new linkages would benefit from diversity among individuals in order to foster novelty and innovation among health care organizations [49]. Spreading innovation, such as addressing obesity as a complex problem, requires new thinkers to connect and share their knowledge with others. The bridging together of clinical practitioners to address the multiple determinants of obesity may improve patient care and establish the conditions necessary for emergence to take place.

Feedback is also an integral part of a system's functioning, and is understood to be essential for successful behavior change [50]. Feedback drives the learning process; by receiving feedback about the effects of action taken, individuals are provided with the information with which to maintain that action or change course [11]. Some of the weakness of traditional health education approaches can be attributed to the absence of built-in processes for generating feedback [11] and feedback loops and delays tend to be ignored or poorly understood when it comes to creating interventions, policies or clinical treatment. Delays in particular can have powerful influence on learning from interventions and developing an evidence base. In the case of obesity, the length of time required to lose a certain amount of weight will vary greatly from individual to individual and successful weight loss may not be equal to reaching one's 'ideal' weight $[32,51]$.
The importance of feedback in the clinical treatment of obesity has been demonstrated through the success of selfmonitoring in modifying behavior $[25,32]$. The power of feedback can be further enhanced in clinical settings through improved patient engagement. Health care is often providerdirected and shows little patient engagement, decreasing opportunities for learning for both parties. Increased participation from all members provides the opportunity to break down barriers between patients and providers [52]. Preference for involvement in decision-making varies among patients; however this may be because they are ill informed about the benefits they stand to gain [23]. Clinicians are also poor at assessing their patients' preferences for involvement [23] and poor patient education and engagement is one of the primary causes of negative treatment outcomes, non-response to medications and poor adherence [53]. Efforts to promote patient activation and engagement are likely to produce better patient outcomes and better care experiences [37]. A similar strategy was piloted in a nursing study where patient outcomes improved using an evidence-based, holistic, person-centered approach to obesity management by helping individuals identify barriers and, as a result, initiate self-care strategies for weight loss [54].

\section{Shifting Paradigms and Goals}

Activities taking place in a clinical setting flow in part from the system's guiding paradigms. A paradigm can be defined as a shared unstated assumption under which a system operates; it is the source of system goals, information flows, feedback and everything else about the system [44]. Paradigm shifts may result over time due to the cumulative effect of changes enacted throughout a system. For example, the shift in perception of tobacco from a socially accepted norm to an undesirable trait in North America was the result of hundreds of smaller changes in policy, health education, treatment options and other areas, all of which pushed attitudes about tobacco toward a tipping point [55]. Treatment practices in obesity can also be considered within the framework of paradigms. Melin and Rossner [25] identify three main overarching approaches that treatment can assume. These are weight modification, modification of other health-related variables beyond weight (i.e., diet and physical activity), and emphasis on changing attitudes among and toward obese individuals. Each of these approaches can be identified with different paradigms, goals and treatment methods. The conversation of which approach is best is taking place in many sectors as policymakers, physicians, and the public grapple with the issue of weight bias and its possibly being perpetuated by the focus on obesity as a social issue [5•]. Many of the issues previously identified in this piece - weight bias, poor communication, effectiveness of treatment - can be better understood and 
addressed through multi-disciplinary teams working from different paradigms, and from improved patient-clinician engagement in order to establish the paradigms and values of the patients themselves.

Best practice suggests that a chronic disease model provides the most useful framework for developing the treatment approaches needed for obesity. The benefits of this model lie in its recognition that the pathogenesis of obesity involves both genetic and environmental influences, that obesity cannot be cured but can be managed, and that relapses occur when treatment is stopped or not followed [19, 25]. As a paradigm of health promotion, the chronic disease model emphasizes life-long intervention with an understanding that relapses will occur and provide learning opportunities [56]. It shifts the focus of behavior change to process rather than outcomes, therefore aligning with methods of treatment that address health-related variables other than body weight. This has the potential to improve patient self-esteem and decrease weight bias. Behavioral treatment, for example, has been shown to have benefits in enhancing patient selfesteem and increasing obese people's ability to cope with adverse consequences regardless of outcomes in regard to changing body weight [25].

Improving education about the complexity of obesity and of systems theory is another means of providing practitioners and patients with improved resources and capacity while shifting treatment paradigms. Nonlinearity, for example, is a characteristic of complex systems, in which changing one variable in a relationship may have inconsistent effects on another [44]. The human body has been shown to adapt to changes in caloric intake and become unpredictable [57], thereby behaving in a nonlinear fashion when it comes to weight loss. This knowledge informs patients and practitioners that it may not be enough to simply eat less and achieve predictable weight loss, reinforcing the fact that some aspects of weight management are beyond the control of the individual. Research suggests that even though health professionals and policymakers understand obesity to be a socioecological problem, they are still more inclined toward individually focused weight management interventions as effective responses [5•]. A stronger understanding among health professionals of the complexities of obesity will be beneficial in health care adopting a more holistic, patient centered model of obesity treatment and management [58]. Clinicians also have a role to play in shaping public discourse about obesity. Negative depictions of obese and overweight people in the media and political discourse have the power to perpetuate weight bias and shape public policy [59], thereby having downstream impacts on health care access and quality. Physicians advocating for the rights of obese patients are helping to shift paradigms away from blaming the individual and toward more patient-friendly, solution-focused perspectives.

\section{Conclusion}

The literature considered in this review suggests that a reductionist approach toward treating obesity as a simple problem has had little effect in reducing obesity trends. Accepting obesity as a complex problem is an important step in working toward solutions that will address the multiple interconnections and elements that contribute to obesity. Systems thinking provides a way forward for resolving health challenges in complex, real world settings. Shifting our paradigms around the causes of obesity is essential for creating a health care system that promotes innovative and collaborative practice for healthcare practitioners and individuals dealing with obesity. The literature suggests that while individual behavior change is at the center of obesity management, an effective health care team is essential to ensuring individuals receive the support, advice and guidance they need to improve their health status.

Acknowledgments Sarah Frood, Lee Johnston, Carrie Matteson, and Diane T. Finegood have received grant support from CIHR and the LiVWELL research group (Grant 31-711031), funded through the Community Trust Endowment Fund at Simon Fraser University.

\section{Compliance with Ethics Guidelines}

Conflict of Interest Sarah Frood declares that she has no conflict of interest.

Lee Johnston declares that she has no conflict of interest.

Carrie Matteson declares that she has no conflict of interest.

Diane T. Finegood declares that she has no conflict of interest.

Human and Animal Rights and Informed Consent This article does not contain any studies with human or animal subjects performed by any of the authors.

Open Access This article is distributed under the terms of the Creative Commons Attribution License which permits any use, distribution, and reproduction in any medium, provided the original author(s) and the source are credited.

\section{References}

Papers of particular interest, published recently, have been highlighted as:

- Of importance

•. Of major importance

1. World Health Organization. Obesity and Overweight Fact Sheet [Internet]. World Health Organization; 2013 [cited 2013 Mar 15]. Available from: http://www.who.int/mediacentre/factsheets/fs311/ en/index.html.

2. Alvaro C, Jackson LA, Kirk S, McHugh TL, Hughes J, Chircop A, et al. Moving Canadian governmental policies beyond a focus on individual lifestyle: some insights from complexity and critical theories. Health Promot Int. 2010;26(1):91-9. 
3. Gortmaker SL, Swinburn BA, Levy D, Carter R, Mabry PL, Finegood DT, et al. Changing the future of obesity: science, policy, and action. Lancet. 2011;378(9793):838-47.

4. Teixeira FV, Pais-Ribeiro JL, Maia ÂR. Beliefs and practices of healthcare providers regarding obesity: a systematic review. Revi da Associação Méd Brasileira. 1992;58(2):254-62.

5. - Greener J, Douglas F, Van Teijlingen E. More of the same? Conflicting perspectives of obesity causation and intervention amongst overweight people, health professionals and policy makers. Soc SciMed. 1982;70(7):1042-9. Examines the perceptions and beliefs around the causes of obesity among individuals, health practitioners and policy makers and makes a case for shifting paradigms as a method to work toward solutions.

6. Stokols D. Translating Social Ecological Theory into Guidelines for Community Health Promotion. Am J Health Prom. 1996;10(4):282-98.

7. Kumanyika S, Jeffery RW, Morabia A, Ritenbaugh C, Antipatis VJ. Obesity prevention: the case for action. Int J Obes Relat Metab Disord. 2002;26(3):425-36.

8. Lake A, Townshend T. Obesogenic environments: exploring the built and food environments. J Royal Soc Promot Health. 2006;126(6): 262-7.

9. Bray GA. The epidemic of obesity and changes in food intake: the Fluoride Hypothesis. Physiol Behav. 2004;82(1):115-21.

10. Epstein LH, Temple JL, Neaderhiser BJ, Salis RJ, Erbe RW, Leddy JJ. Food reinforcement, the dopamine D2 receptor genotype, and energy intake in obese and nonobese humans. Behav Neurosci. 2007;121(5):877-86.

11. Hamid T. Thinking in circles about obesity: applying systems thinking to weight management. New York: Springer; 2009.

12. Vandenbroeck P., Goossens J., Clemens M. Foresight tackling obesities: Future choices - obesity systems atlas. 2007.

13. Finegood DT. The Complex Systems Science of Obesity. In: Cawley J, editor. Handbook of the Social Science of Obesity. New York: Oxford University Press; 2011.

14. Huang TT, Drewnosksi A, Kumanyika S, Glass TA. A systemsoriented multilevel framework for addressing obesity in the $21 \mathrm{st}$ century. Prev Chron Dis. 2009;6(3):A82.

15. Plsek PE, Greenhalgh T. Complexity science: The challenge of complexity in health care. BMJ (Clinical research edn). 2001;323(7313):625-8.

16. Buchwald H, Avidor Y, Braunwald E, Jensen MD, Pories W, Fahrbach K, et al. Bariatric surgery: a systematic review and metaanalysis. JAMA. 2004;292(14):1724-37.

17. Norris SL, Zhang X, Avenell A, Gregg E, Schmid CH, Lau J. Pharmacotherapy for weight loss in adults with type 2 diabetes mellitus. Cochrane Data System Rev. 2005;1, CD004096.

18. Lau DCW, Douketis JD, Morrison KM, Hramiak IM, Sharma AM. Ehud Ur for members of the OCCPGEP. 2006 Canadian clinical practice guidelines on the management and prevention of obesity in adults and children [summary]. Can Med. 2007;176(8):S1-13.

19. Klein S. Clinical obesity issues from an internist's perspective. Obes Res. 2002;10 Suppl 1:87S-8.

20. Mold F, Forbes A. Patients'and professionals' experiences and perspectives of obesity in health-care settings: a synthesis of current research. Health Expect. 2011;7:1-24.

21. Leverence RR, Williams RL, Sussman A, Crabtree BF. Obesity counseling and guidelines in primary care: a qualitative study. Am J Preventive Med. 2007;32(4):334-9.

22. Ferrante JM, Piasecki AK, Ohman-Strickland PA, Crabtree BF. Family physicians' practices and attitudes regarding care of extremely obese patients. Obesity. 2009;17(9):1710-6.

23. Robinson A, Thomson R. Variability in patient preferences for participating in medical decision making: implication for the use of decision support tools. QHC. 2001;10 Suppl 1:i34-8.

24. Rodondi N, Humair J-P, Ghali WA, Ruffieux C, Stoianov R, Seematter-Bagnoud L, et al. Counselling overweight and obese patients in primary care: a prospective cohort study. Eur J Cardiovasc Prev Rehabil. 2006;13(2):222-8.

25. Melin I, Rössner S. Practical clinical behavioral treatment of obesity. Patient Educ Couns. 2003;49(1):75-83.

26. •- Finegood DT. The importance of systems thinking to address obesity. Nestlé Nutr Inst Work Ser. 2012;73:123-41. Explores obesity as a complex problem and gives examples of theoretical frameworks for moving forward.

27. Bar-Yam Y. Making Things Work: Solving Complex Problems in a Complex World. United States of America: NECSI - Knowledge Press; 2004.

28. Brownell KD, Kersh R, Ludwig DS, Post RC, Puhl RM, Schwartz $\mathrm{MB}$, et al. Personal responsibility and obesity: a constructive approach to a controversial issue. Health Affairs (Project Hope). 2010;29(3):379-87.

29. Nothwehr F, Yang J. Goal setting frequency and the use of behavioral strategies related to diet and physical activity. Health Ed Res. 2007;22(4):532-8.

30. Pearson ES. Goal setting as a health behavior change strategy in overweight and obese adults: a systematic literature review examining intervention components. Patient Educ Couns. 2012;87(1):32-42.

31. Shilts MK, Horowitz M, Townsend MS. Goal setting as a strategy for dietary and physical activity behavior change: a review of the literature. Am J Health Promot: AJHP. 2004;19(2):81-93.

32. Foster GD. Clinical implications for the treatment of obesity. Obesity (Silver Spring, Md). 2006;14 Suppl 4:182S-5.

33. Glasgow RE, Emont S, Miller DC. Assessing delivery of the five "As" for patient-centered counseling. Health Promot Int. 2006;21(3):245-55.

34. Jay M, Gillespie C, Schlair S, Sherman S, Kalet A. Physicians' use of the $5 \mathrm{As}$ in counseling obese patients: is the quality of counseling associated with patients' motivation and intention to lose weight? BMC Health Serv Res. 2010;10:159.

35. Burns C., Winhall J. Red health report: Design notes 01 - the diabetes agenda. London, UK; 2006.

36. Merth T. "Dealing" with. Complexity: Construction and Analysis of a Card Based Communication Tool for Patients with Obesity. Simon Fraser University; 2011.

37. Hibbard JH, Greene J. What the evidence shows about patient activation: better health outcomes and care experiences; fewer data on costs. Health Affairs (Project Hope). 2013;32(2):207-14.

38. Wennberg DE, Marr A, Lang L, O'Malley S, Bennett G. A randomized trial of a telephone care-management strategy. New Engl JMed. 2010;363(13):1245-55.

39. • Koh HK, Brach C, Harris LM, Parchman ML. A proposed "health literate care model" would constitute a systems approach to improving patients' engagement in care. Health Affairs (Project Hope). 2013;32(2):357-67. This study provides a concrete example of applying systems thinking for addressing health outcomes in patients. It uses health literacy as an organizational value for improving patient self-management, delivery system design, shared decision making support and clinical information systems.

40. Greene J, Hibbard JH. Why does patient activation matter? An examination of the relationships between patient activation and healthrelated outcomes. J General Intern Med. 2012;27(5):520-6.

41. Begun JW, Zimmerman B, Dooley K. Health Care Organizations as Complex Adaptive Systems. In: Mick SM, Wyttenback M, editors. Advances in health care organization theory. San Francisco: JosseyBass; 2003. p. 253-88.

42. Norman CD. Health promotion as a systems science and practice. $\mathrm{J}$ Evaluat in Clin Pract. 2009;15(5):868-72.

43. Cunningham FC, Ranmuthugala G, Plumb J, Georgiou A, Westbrook JI, Braithwaite J. Health professional networks as a vector for improving healthcare quality and safety: a systematic review. BMJ Quality Wafety. 2012;21(3):239-49.

44. Meadows DH. Thinking in systems: a primer. White River: Chelsea Green Publishing; 2008. p. 240. 
45. Leischow SJ, Milstein B. Systems thinking and modeling for public health practice. Am J Public Health. 2006;96(3):403-5.

46. Best A, Holmes B. Systems thinking, knowledge and action: towards better models and methods. Policy. 2010;6(2):145-59.

47. Iles V, Sutherland K. Organisational change: a review for health care managers, professionals and researchers. London, UK; 2001.

48. Wheatley M, Frieze D. Using Emergence to Take Social Innovation to Scale. The Berkana Institute. 2006;1-7.

49. Mascia D, Cicchetti A, Fantini MP, Damiani G, Ricciardi W. Physicians' propensity to collaborate and their attitude towards EBM: a cross-sectional study. BMC Health Serv Res. 2011;11:172.

50. Willis CD, Riley BL, Best A, Ongolo-Zogo P. Strengthening health systems through networks: the need for measurement and feedback. Health Policy Plan. 2012;27 Suppl 4:iv62-6.

51. Stubbs J, Whybrow S, Teixeira P, Blundell J, Lawton C, Westenhoefer $\mathrm{J}$, et al. Problems in identifying predictors and correlates of weight loss and maintenance: implications for weight control therapies based on behaviour change. Obes Rev. 2011;12(9):688-708.

52. Swanson RC, Cattaneo A, Bradley E, Chunharas S, Atun R, Abbas $\mathrm{KM}$, et al. Rethinking health systems strengthening: key systems thinking tools and strategies for transformational change. Health Policy Plan. 2012;27 Suppl 4:iv54-61.

53. Snyderman R, Dinan MA. Improving health by taking it personally. JAMA. 2010;303(4):363-4.

54. Goldie C, Brown J. Managing obesity in primary care. Nurs Times. 2012;108(1/2):6-14.

55. Leischow SJ, Best A, Trochim WM, Clark PI, Gallagher RS, Marcus SE, et al. Systems thinking to improve the public's health. Am J Preventive Med. 2008;35(2 Suppl):S196-203.

56. D.C.W. Lau, J.D. Douketis, K.M. Morrison, I.M. Hramiak, A.M. Sharma, Ehud Ur for members of the OCCPGEP. 2006 Canadian clinical practice guidelines on the management and prevention of obesity in adults and children [summary]. Can Med. 2007;176(8).

57. Hall KD. Predicting metabolic adaptation, body weight change, and energy intake in humans. Am J Physiol Endocrinol Metab. 2010;298(3): E449-66.

58. Brown J, Wimpenny P. Developing a holistic approach to obesity management. Int J Nurs Pract. 2011;17(1):9-18.

59. Puhl RM, Heuer CA. Obesity Stigma: Important Considerations for Public Health. Am J Public Health. 2010;100:1019-28. 